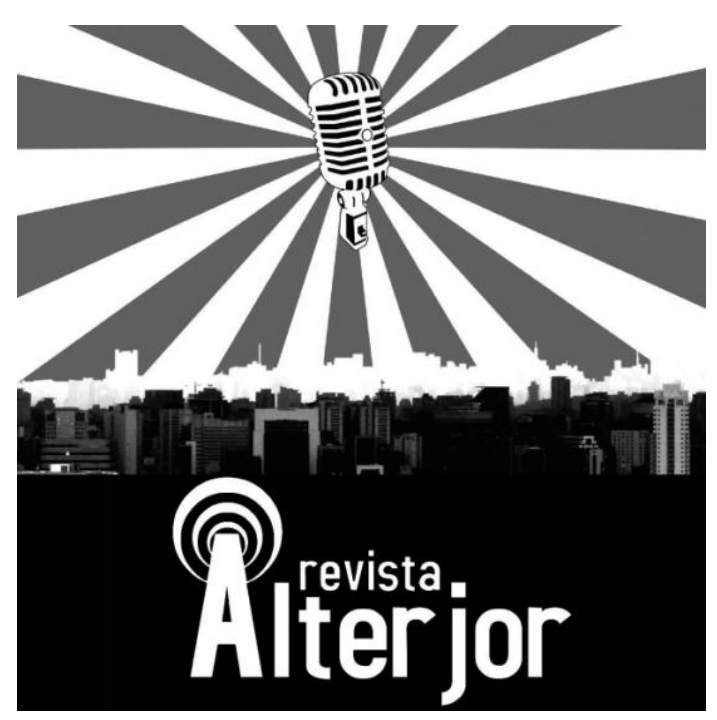

\title{
ASSOCIAÇÃO LATINO-AMERICANA DE COMUNICAÇÃO E EDUCAÇÃO POPULAR (ALER) - FRAGMENTOS E CONTEXTOS
}

\author{
Vivian de Oliveira Neves Fernandes ${ }^{1}$
}

RESUMO: Este artigo busca descrever alguns dos principais fatos da história da Associação Latino-Americana de Comunicação e Educação Popular (ALER) ao longo de suas quase cinco décadas, que foram relacionados por meio de análise de documentos e pela entrevista com o coordenador-geral da rede, Hugo Ramírez. Reunindo rádios populares latino-americanas desde 1972, essa rede passou por cinco fases principais: da alfabetização por meio do rádio, do rádio popular na transformação da sociedade, de redes informativas e transformações tecnológicas, dos projetos políticos comunicativos e, a atual, na aposta pelo Buen Vivir.

PALAVRAS-CHAVE: Associação Latino-Americana de Educação e Comunicação Popular (ALER). Rede de Rádios Populares. Buen Vivir.

ABSTRACT: This article seeks to describe some of the main facts of the Latin American Association of Popular Education and Communication (ALER) over its nearly five decades of history, that were listed through document analysis and an interview with the network's general coordinator, Hugo Ramírez. Bringing together popular Latin American radio stations since 1972, this network has gone through five phases: from education through radio, popular radio in the transformation of society, from informational networks and technological transformations, from communicative political projects, and the current one, in the bet for Buen Vivir.

KEYWORDS: Latin American Association of Popular Education and Communication (ALER).Popular Radio Networks. Buen Vivir.

\footnotetext{
${ }^{1}$ Jornalista, mestra em Ciências da Comunicação pela Escola de Comunicações e Artes da Universidade de São Paulo (ECA-USP) e doutoranda no programa de Pós-graduação em Ciências da Comunicação da mesma instituição.
}

Revista ALTERJOR

Grupo de Estudos Alterjor:Jornalismo Popular e Alternativo (ECA-USP)

Ano 10 Volume 02 Edição $22 \quad$ Julho-Dezembro de 2020

Avenida Professor Lúcio Martins Rodriģues, 443, Cidade Universitária, São Paulo, CEP: 05508-020 


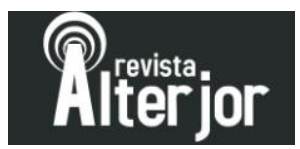

\section{INTRODUÇÃO}

A Associação Latino-Americana de Comunicação e Educação Popular (ALER), criada em 1972, se apresenta como uma rede de rádio populares e experiências de comunicação de distintos países da região e que tem como missão "educar e comunicar paixão pela vida e compromisso com a felicidade dos povos latino-americanos" ${ }^{\text {2. Ao }}$ longo de seus cerca de 50 anos de história, a ALER “é conhecida e respeitada por sua capacidade para definir e redefinir (...) seus projetos e estratégias educativas e comunicativas, para responder às situações de mudanças na América Latina e Caribe e no mundo"33 (ALER, 2012, p. 1, tradução nossa).

A trajetória da ALER pode ser dividida em cinco fases principais: com o início marcado pelas escolas radiofônicas; caminhando pela formulação do conceito de rádio popular e sua atuação na sociedade; da criação de redes informativas e do uso de novas tecnologias; pela construção de projetos políticos comunicativos; e, neste momento, na aposta pelo Buen Vivir. As mudanças ao longo dessas décadas são compreendidas pela Associação como uma forma de manter sua pertinência e atuação:

"A ALER sempre esteve alerta para manter sua coerência interna para ser eficiente; e sua correspondência com o contexto, para ser relevante e incidente. A construção conjunta entre as associadas nesses processos tem sido o mecanismo chave para garantir sua vida e sustentabilidade." ${ }^{4}$ (ALER, 2012, p. 1, tradução nossa)

Para a reconstituição histórica e análise propostas neste texto, partiu-se da revisão bibliográfica - realizada a partir de artigos e livros publicados sobre o tema, documentos internos e publicações da Associação - e de entrevista semiestruturada - na

\footnotetext{
2 Missão expressa na página web da ALER. Disponível em: https://www.aler.org/index.php/node/1. Acesso: 14 de fevereiro de 2019. No original em espanhol: "educar y comunicar pasión por la vida y compromiso con la felicidad de los pueblos latinoamericanos".

${ }^{3}$ No original em espanhol: "es conocida y respetada por su capacidad para definir y redefinir, (...) sus proyectos y estrategias educativas y comunicativas, para responder a las situaciones cambiantes en ALC y el mundo".

${ }^{4}$ No original em espanhol: "ALER siempre estuvo alerta para mantener su coherencia interna para ser eficiente; y su correspondencia con el contexto, para ser relevante e incidente. La construcción conjunta entre las socias en esos procesos ha sido el mecanismo clave para garantizar su vida y sostenibilidad".
} 


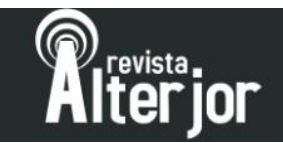

qual partiu-se dos eixos orientadores baseados nas fases históricas dessa rede, mas com um relativo grau de flexibilidade no formato das perguntas e nos termos utilizados (BERNAL, 2010) - com o seu atual coordenador-geral, Hugo Ramírez. Compreende-se a relevância da ALER para a história do rádio latino-americano por se tratar de um projeto de articulação de meios populares na região com duração de quase 50 anos.

\section{Primeira fase: alfabetização pelo rádio (1972-1982)}

Surgida em 1972, a Associação Latino-Americana de Comunicação e Educação Popular (ALER) teve até 1982 o primeiro período de história. Foi no município de Sutatenza, no departamento de Boyacá, na Colômbia, onde surgiu esta rede, em 22 de setembro daquele ano.

No entorno agressivo das ditaduras, dez instituições ${ }^{5}$ de origem católica montam projetos de educação formal dirigidos a áreas rurais que estavam completamente marginalizadas dos centros de desenvolvimento. Os beneficiários são os camponeses e indígenas. A rádio é um meio para divulgar as aulas e estender o trabalho como escola. ALER: "A associação latino-americana de educação radiofônica"”. (ALER, 2012, p. 3, tradução nossa)

Do nome que contemplava o termo "Educação Radiofônica", que dá origem à sigla ALER, os membros da Associação, na sua assembleia geral de 2016, decidem por trocar o final por Comunicação e Educação Popular, baixo a justificativa de que a atuação e a abrangência da rede não se circunscrevem somente ao rádio, mas em múltiplas formas de comunicação.

\footnotetext{
${ }^{5}$ Há um número divergente sobre a quantidade de rádios que deram início a ALER, pois segundo o presidente e o vice-presidente da Associação nos anos 1980, em entrevista à revista CHASQUI (1984), seriam 18 as emissoras que começaram essa rede.

${ }^{6}$ No original em espanhol: "En el entorno agresivo de las dictaduras, diez instituciones de origen católico, montan proyectos de educación formal dirigidos hacia áreas rurales que estaban completamente marginadas de los centros de desarrollo. Los beneficiarios son los campesinos e indígenas. La radio es un medio para divulgar las clases y extender la labor como escuela. ALER: 'la asociación latinoamericana de educación radiofónica'."
}

Revista ALTERJOR

Grupo de Estudos Alterjor: Jornalismo Popular e Alternativo (ECA-USP)

Ano 10 Volume 02 Edição $22 \quad$ Juho- Dezembro de 2020

Avenida Professor Lúcio Martins Rodrig̉ues, 443, Cidade Universitária, São Paulo, CEP: 05508-020 
Alguns elementos da primeira fase da Associação estão descritos na entrevista intitulada “Once años de ALER”, concedida por Javier Velasco ${ }^{7}$, presidente da rede à época, e Ricardo Silguero ${ }^{8}$, seu então vice-presidente, para a revista Chasqui, em 1984. $\mathrm{Na}$ ocasião, os dirigentes da ALER apontaram que as escolas radiofônicas surgiram por parte de setores da Igreja Católica, motivados pela situação de alto índice de analfabetos nos países latino-americanos e que se encontravam em um "isolamento" provocado pelo fato de não saberem ler e escrever. Desta inquietação inicial e de experiências nesse modelo na região, foram se desenvolvendo emissoras em distintos países.

A maioria das rádios, se não todas as que fizeram parte da ALER em sua década inicial, estava ligada a setores da Igreja Católica que defendiam a Teologia da Libertação, característica fundacional da Associação que é levantada por Hugo Ramírez ${ }^{9}$, atual coordenador-geral da rede (informação verbal), ao elencar fatos da trajetória da articulação.

Recordo que, ao final dos anos 60, começou toda essa mudança também na Igreja Católica, de ter uma Igreja mais progressista, da Teologia da Libertação, que foi produto de tudo o que é o Concílio

\footnotetext{
${ }^{7}$ Javier Velasco é espanhol-boliviano, presidente da ALER em 1984. Iniciou seu trabalho na Ação Cultural Loyola, em 1979, em departamentos bolivianos, dedicando-se à educação e à organização popular camponesa.

${ }^{8}$ Ricardo Silguero é venezuelano, vice-presidente da ALER em 1984. Era sacerdote da Arquidiocese de Mérida, com dedicação à educação e à organização cooperativa, e se especializou em educação de adultos. Foi ao longo de décadas diretor da Rádio Occidente, em Mérida.

${ }^{9}$ Hugo Ramírez, comunicador popular peruano que, desde 2016, é coordenador-geral da ALER, com sede em Quito (Equador), concedeu uma entrevista a esta pesquisa em 13 de janeiro de 2020.

${ }^{10}$ No original em espanhol: "Recuerdo que al final de los años 60 empezó todo ese cambio también en la Iglesia Católica, de tener una Iglesia más progresista, de la Teología de la Liberación, que fue producto de todo lo que es el Concílio Vaticano Segundo, y después las conferencias de Puebla, de Medellín, que dieron una gran importancia a la opción preferencial por los pobres, y como la comunicación también tenía que tener un lugar de debate porque era una dimensión y un instrumento importante precisamente para generar esos acompañamientos de la Iglesia en términos de su trabajo pastoral y de opción preferencial por los pobres."
} 


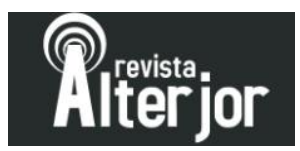

O cenário em que se desenvolveu a ALER neste seu início tem relação com a importância e a incidência do rádio na América Latina, como explica o editorial da edição de número 10 da Revista Chasqui intitulado "La Radio Educativa en América Latina", escrito por Luis E. Proaño (1984). De um sentido mais marcadamente auxiliar em processos de alfabetização, em seu início, o rádio educativo latino-americano passou a descobrir as potencialidades e linguagens próprias desse meio no processo educativo, e, como um terceiro momento, o papel do rádio começou a ser concebido como "uma intercomunicação, na qual a participação gradual conduz necessariamente à organização popular"11.

A trajetória da ALER também se insere nessa descrita pelo rádio educativo e popular na região. A ideia de formar uma rede para construir processos de alfabetização e dar um passo adiante para a autonomia, a organização e a formação de consciência crítica, a partir de pilares de uma práxis transformadora, guarda relação com a ideia de solidariedade como uma "atitude radical" trazida por Paulo Freire em sua obra Pedagogia do Oprimido (2005): “A solidariedade verdadeira com ele está em com eles lutar para a transformação da realidade objetiva que os faz ser este 'ser para outro"” (p. 39-40, itálico do autor).

E esse desafio também estava colocado para as associadas da ALER. De um conjunto de emissoras que se caracterizavam como escolas radiofônicas em educação formal, as rádios foram buscando outros métodos de ensino, com um sentido freireano de estar em diálogo com o povo e buscar abrir caminhos para a organização popular, em que "a alfabetização e a educação de adultos pareciam ser a solução de fundo para corrigir a crescente desigualdade social"12 (ALER, 1993, p. 8, tradução nossa).

E essa movimentação também se deveu pelo contexto que circundava as rádios, que iniciou com um furor revolucionário na América Latina a partir da Revolução Cubana (1959). Em contraposição a isso, os Estados Unidos buscaram exercer seu

\footnotetext{
${ }^{11}$ PROAÑO (1984), p. 1, tradução nossa. No original em espanhol: "una intercomunicación, en la que la participación gradual conduce necesariamente a la organización popular".

${ }^{12}$ No original em espanhol: "La alfabetización y la educación de adultos parecían ser la solución de fondo para corregir la creciente desigualdad social".
} 
domínio no continente por meio da Aliança para o Progresso e outras iniciativas. A Comissão Econômica para a América Latina (Cepal), por exemplo, passou a reavaliar suas teorias iniciais mais alinhadas com os norte-americanos e se tornou mais crítica frente ao novo cenário, pontuando o caráter de dependência econômica a que eram submetidos os países ao sul dessa potência imperialista. Outro fator contextual marcante eram as ditaduras militares que iniciavam ou que tomavam formas ainda mais brutais em muitos países da região.

E, na análise feita pela própria ALER (1993), se desencadeiam reflexões importantes nesse sentido, como: "O problema [da América Latina] era muito mais profundo. Suas raízes penetravam em uma história de séculos de dominação e dependência. E as soluções iam muito além do que só a ação educativa". No que se complementa como resultado de que "esta crise levou a novos apontamentos. As estruturas sociais pediam mudanças radicais e não só correções"13 (p. 8-9, tradução nossa). Assim, as emissoras parte da rede eram estimuladas não só a pensar processos de alfabetização, mas a garantir a participação popular no rádio, gerando assim engajamento em processos de formação de consciência crítica e de transformação da realidade.

As ações da ALER foram concebidas, conforme apresentou Silguero (1984), como um "crescimento na comunicação, na educação e na organização do povo, mas não como ações isoladas ou paralelas", mas que caminham juntas, pois uma depende da outra. E, completou Velasco (1984), “para trabalhar neste nível, é necessário ter um profundo respeito ao projeto do povo. [...] Tem-se que escutar a tendência, os desejos, as aspirações, as lutas do povo, para por-se respeitosamente ao seu lado, o acompanhando"14 (p. 10-11, tradução nossa).

\footnotetext{
${ }^{13}$ No original em espanhol: "El problema era mucho más profundo. Sus raíces penetraban en una historia de siglos de dominación y dependencia. Y las soluciones iban mucho más allá que la sola acción educativa". E: "Esta crisis llevó a nuevos planteamientos. Las estructuras sociales pedían cambios radicales y no sólo correctivos".

14 No original em espanhol: "como un crecimiento en la comunicación, en la educación y en la organización del pueblo, pero no como acciones aisladas y paralelas"; "para trabajar a este nivel, es necesario tener un profundo respecto al proyecto del pueblo"; "Hay que auscultar la tendencia, los deseos, las aspiraciones, las luchas del pueblo, para ponerse respetuosamente a su lado, acompañándole”.
} 


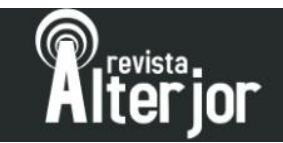

Em Pedagogia do Oprimido, Paulo Freire (2005) compartilha de semelhante visão quando aponta que "crer no povo é a condição prévia, indispensável, à mudança revolucionária. Um revolucionário se reconhece mais por esta crença no povo, que o engaja, do que por mil ações sem ela”. E, a partir do laço de irmandade criado com o povo a que se propõe a ALER, pode-se trazer o que ensinou Freire: "A confiança vai fazendo os sujeitos dialógicos cada vez mais companheiros na pronúncia do mundo" (p. 53, itálico do autor).

\section{Segunda fase: Rádio Popular para transformação social (1982-1992)}

Pouco mais de uma década de sua criação, já nos anos 1980, a ALER contava com 42 afiliadas em 17 países (CHASQUI, 1984, p. 4). Nesta, que é tida como a segunda geração da Associação, que abrange o período de 1982 a 1992, o Rádio Popular toma forma como um conceito teórico em desenvolvimento e de identificação desse conjunto de emissoras, como eles próprios definiram e complementaram: "Entra a Rádio Popular em ação, participando nos processos de transformações, às vezes como protagonista." ${ }^{15}$ (ALER, 2012, p. 3, tradução nossa).

O contexto em que se apresentou essa nova leitura era o de fim de ditaduras militares na região e emergência de novas formas de organização popular de base. Também como caracterização do momento, foi pontuado que se acelerou o processo de urbanização e a pobreza passou a se concentrar nas cidades (ALER, 2012), o que indicava que as rádios afiliadas da ALER se diversificavam mais, passando a ampliar para além das áreas rurais, dos camponeses e indígenas o seu foco, e chegando até os trabalhadores urbanos e tratando sobre temas das cidades.

O modelo econômico neoliberal e as consequências negativas que este sistema passou a gerar na população mais pobre também despontaram no cenário da América Latina, o que, para a ALER (1993), significou manifestar "a necessidade de seguir optando por um trabalho a favor dos amplos setores imersos em processos de

\footnotetext{
${ }^{15}$ No original em espanhol: "Entra la Radio Popular en acción, participando en los procesos de cambios, a veces como protagonistas."
} 
empobrecimento e sobrevivência" ${ }^{16}$ (p. 14, tradução nossa). Frente à lógica de mercado e de competitividade, cabia às rádios da Associação "o desafio de contribuir para a construção de um futuro mais humano"17 (p. 14, tradução nossa), e isso se daria por meio do povo organizado em distintas esferas da sociedade civil.

As rádios entendem que seu projeto comunicativo e sua contribuição educativa devem buscar uma vinculação estreita com muitas outras entidades que promovem o desenvolvimento integral da sociedade. Nessa vinculação, a rádio vai assumindo um papel mais protagônico e público. Sai de seu lugar tímido e marginal para ocupar um espaço de autoridade na sociedade. Cria novos programas de opinião pública, fomenta o diálogo e o amplo debate sobre temas que podem beneficiar as maiorias empobrecidas. Divulgar as denúncias e propostas da população, com a intenção de influenciar na tomada de decisões sobre temas de interesse popular. Enfim, a rádio educativa pretende colaborar com força para a construção de sociedades realmente democráticas. ${ }^{18}$ (ALER, 1993, p. 14-15, tradução nossa)

No que tange o conceito de rádio popular, Maria Cristina Mata, comunicadora argentina e que à época era parte do Conselho Executivo da ALER, em artigo publicado na Revista Chasqui (1993), defende o uso do termo popular em comparação a comunitário ou outros. Para ela, o termo comunitário refere-se a uma noção de pertencimento a uma comunidade que pode expressar-se de variadas formas - de populações particulares a culturas locais -, mas não demarca, necessariamente, a posição central que ocupa o sujeito ou os setores populares, ou seja, não "implica um posicionamento global frente a um sistema econômico-social no qual ditos setores sem importar de que grupo se trate ou onde estejam localizados geograficamente - são

\footnotetext{
${ }^{16}$ No original em espanhol: "La necesidad de seguir optando por un trabajo en favor de los amplios sectores sumergidos en procesos de empobrecimiento y sobrevivencia".

${ }^{17}$ No original em espanhol: "El reto de contribuir a la construcción de un futuro más humano".

${ }^{18}$ No original em espanhol: "Las radios entienden que su proyecto comunicativo y su aporte educativo deben buscar una vinculación estrecha con muchas otras entidades que promueven el desarrollo integral de la sociedad. En esa vinculación la radio va asumiendo un rol más protagónico y público. Sale de su ubicación tímida y marginal para ocupar un espacio de autoridad en la sociedad. Crea nuevos programas de opinión pública, fomenta el diálogo y el debate amplio sobre temas que pueden beneficiar a las mayorías empobrecidas. Divulgar las denuncias y propuestas de la población con la intención de influir en la toma de decisiones sobre temas de interés popular. En fin, la radio educativa pretende colaborar con fuerza en la construcción de sociedades realmente democráticas”.
}

Revista ALTERJOR

Grupo de Estudos Alterjor:Jornalismo Popular e Alternativo (ECA-USP)

Ano 10 Volume 02 Edição $22 \quad$ Juho- Dezembro de 2020

Avenida Professor Lúcio Martins Rodrig̉ues, 443, Cidade Universitária, São Paulo, CEP: 05508-020 


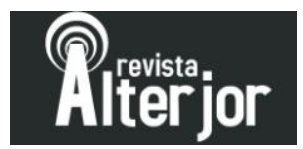

marginalizados ou excluídos também globalmente do poder" ${ }^{\prime 19}$ (MATA, 1993, p. 59, tradução nossa). Nesse sentido, Maria Mata reivindicou o uso do termo rádio popular como uma forma de caracterizar politicamente a posição dessas emissoras que atuam dentro do campo popular e da disputa da opinião pública com "estratégias orientadas à necessidade de desenhar projetos globais de transformação" ${ }^{20}$.

$\mathrm{Na}$ ampliação da atuação dessas emissoras e assumindo o caráter de rádio popular, reunindo o educativo ao potencial comunicativo, apresentou-se um novo desafio, o de ampliar o número de comunicadores populares, formados política e tecnicamente para disputar a hegemonia na comunicação. Nesta fase da ALER, surgem, assim, os processos de capacitação e as cartilhas de formação em produção radiofônica.

Para refletir sobre esse momento, na obra Una Pedagogía de la Comunicación (2002), de Mario Kaplún, trabalha-se a ideia-síntese de que "para cada tipo de educação, corresponde uma determinada concepção e uma determinada prática de comunicação",21 (p.15, tradução nossa). Nesse sentido, a ALER buscou desenvolver um trabalho de formação para ampliar o número de emissores em rádios populares, por meio de seus manuais ou oficinas presenciais, evocando que o povo deva ser o sujeito central da comunicação popular. Bebendo na fonte da educação popular e libertadora freireana, a ALER estabeleceu as bases para sua capacitação de comunicadores nos Manuales de Capacitación, que totalizaram catorze volumes lançados em sua primeira edição no espanhol entre 1984 e 1995. Nos anos 1990 e 2000, diversas reedições foram feitas, com publicações em distintos países, inclusive no Brasil.

O primeiro Manual Radiofônico em espanhol foi "La Entrevista", de 1984. A sua versão revisada de 2009 assim foi apresentada por uma de suas afiliadas, a Associação de Rádios e Programas Participativos de El Salvador (ARPAS):

\footnotetext{
${ }^{19}$ No original em espanhol: "Implica un posicionamiento global frente a un sistema económico-social en el cual dichos sectores - sin importar de qué grupo se trate o dónde estén ubicados geográficamente - son marginados o excluidos también globalmente del poder".

${ }^{20}$ Ibidem, tradução nossa. No original em espanhol: "estrategias orientadas a la necesidad de diseñar proyectos globales de cambio.

${ }^{21}$ No original em espanhol: "A cada tipo de educación corresponde una determinada concepción y una determinada práctica de la comunicación".
} 
Tendo como premissa fundamental a necessidade de construção de espaços para expressar as vozes, opiniões e também os ritmos de nossos povos, este primeiro exemplar propõe o formato da entrevista como ferramenta para conhecer o que pensam as pessoas sobre a realidade diária. Este material busca enfatizar a importância do diálogo como base de uma boa comunicação, do conhecimento do entorno das audiências, a relevância de partir da escuta, do valor das opiniões de quem entrevistamos, para colaborar, assim, para que a palavra do povo nasça. ${ }^{22}$

Além dos manuais, nesse período, a Associação promoveu uma série de oficinas e cursos de capacitação em comunicação e jornalismo popular por diversas cidades da América Latina, uma "capacitação e formação em território, no próprio terreno, nas próprias emissoras, de suas associadas" ${ }^{23}$, como conta Hugo Ramírez ${ }^{24}$ (informação verbal), atual coordenador-geral da Associação. De acordo com ele, esse processo de formação durou até meados dos anos 1990, "quando decidem aqui na ALER dar força às coordenadoras nacionais de rádio, que as coordenadoras sejam de fato os pontos que comecem a formação e a ALER seja a instância continental que apoia as coordenadoras",25 (informação verbal).

Outro marco desse período é que, além de avançar na proposta de formação de comunicadores populares, a ALER põe força na produção de material jornalístico próprio, com o Alerta, uma produção impressa, e, posteriormente, o Informativo Tercer Mundo, distribuído por meio de fitas cassete enviadas por correio. Paralelo ao envio do informativo, começa a se formar a Rede de Correspondentes, com comunicadores de

\footnotetext{
22 Apresentação do Manual da ALER - A Entrevista. Disponível em: https://arpas.org.sv/manuales-dealer/. Acesso em: 15 de agosto de 2019. No original em espanhol: "Teniendo como premisa fundamental la necesidad de construcción de espacios para expresar las voces, opiniones y también los ritmos de nuestros pueblos, este primer ejemplar propone el formato de la entrevista como herramienta para conocer qué piensan las personas sobre la realidad de todos los días. Este material busca enfatizar la importancia del diálogo como base de una buena comunicación, del conocimiento del entorno de las audiencias, la relevancia de partir de la escucha, del valor de las opiniones de quienes entrevistamos, para colaborar así, a que la palabra del pueblo nazca".

${ }^{23}$ No original em espanhol: "Capacitación y formación en território, en el propio terreno, en las propias emisoras, de sus asociadas".

${ }^{24}$ Hugo Ramírez, comunicador popular peruano que, desde 2016, é coordenador-geral da ALER, com sede em Quito (Equador), concedeu uma entrevista a esta tese em 13 de janeiro de 2020.

${ }^{25}$ No original em espanhol: "Cuando deciden más bien aquí en ALER darle fuerza a las coordinadoras nacionales de rádio, que las coordinadoras sean más bien los puntos que empiezan a formar y más bien ALER como instancia continental apoya las coordinadoras".
} 


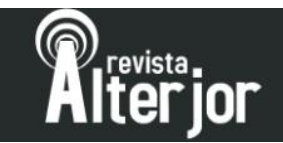

distintas emissoras parte da rede, que compartilhavam entre si boletins radiojornalísticos. Estes foram os passos iniciais do que seria uma atuação central da ALER nas décadas seguintes e que também daria forma à rede satelital de rádios, a Alred, e uma série de outras produções e articulações construídas em cooperação com as associadas.

\section{Terceira fase: Redes informativas e novas tecnologias (1992-2001)}

$\mathrm{Na}$ expansão da formação, da produção noticiosa e da articulação de novas rádios, a ALER entra em sua terceira geração, de 1992 a 2001, com cerca de 80 emissoras associadas. Esse é o período em que o fortalecimento do trabalho em rede para produção informativa ocorre, com a articulação de uma dedicada a correspondentes jornalísticos e outra formada pelos indígenas kichwas (do Equador) e quechuas (de Bolívia e Peru), e a implementação de um sistema satelital, a América Latina em Rede (Alred), ou como definiram: "a rede das redes", que viria a potencializar o trabalho das rádios populares.

O contexto que marca essa fase, segundo a Associação, era o de fortalecimento das democracias formais - após um período de ditaduras e de redemocratização nos países latino-americanos -, ao mesmo tempo em que se fortalece o projeto neoliberal. Na avaliação de Hugo Ramírez ${ }^{26}$, coordenador-geral da ALER desde 2016, a década de 1990 foi muito dura para os setores populares, por um lado com as políticas econômicas neoliberais de aprofundamento da pobreza e, por outro, agudização dos conflitos sociais que puxaram a Associação para que ela tivesse uma atuação precisa e combativa.

Em um contexto bem complicado, porque os anos 90 foram os tempos, como dizemos, da longa noite escura do neoliberalismo, da imposição dos "pacotaços", as políticas econômicas [neoliberais] dos governos que chegaram em distintos países, em quase toda a América Latina, enfim, com tudo o que significou o aprofundamento da

\footnotetext{
${ }^{26}$ Hugo Ramírez, comunicador popular peruano que, desde 2016, é coordenador-geral da ALER, com sede em Quito (Equador), concedeu uma entrevista em 13 de janeiro de 2020.
} 
pobreza como consequência precisamente dessas políticas econômicas. ${ }^{27}$ (informação verbal)

Para alcançar seus objetivos em meio ao novo momento histórico, a ALER e suas rádios associadas fizeram uso das novas tecnologias da informação e da comunicação, por meio das quais a Associação "tem um serviço radiofônico de interconexão intercontinental, cujos suportes principais são o satélite e a internet" ${ }^{28}$. A necessidade de troca de experiências e formação, além da produção de materiais radiofônicos, levou com que, em 1997, fosse lançada a América Latina em Rede (Alred) Satelital, que também ganhou o nome de Sistema Intercontinental de Comunicação Radiofônica (SICR).

A proposta de conexão via satélite surgiu na ALER como uma estratégia e uma metodologia de trabalho para compartilhar as produções radiofônicas das afiliadas, diante de um contexto em que muitas delas possuíam escassos recursos financeiros, assim fazer com que essa rede fosse um "espaço de encontro das rádios educativas, populares, comunitárias e participativas" da América Latina e do Caribe, para que tenham incidência política no continente e no mundo"29 (ALER, 2012, p. 4-5, tradução nossa).

Ao salto tecnológico que veio com a utilização do satélite, soma-se a Rede de Correspondentes, formada para a produção dos conteúdos jornalísticos, que já vinha se desenvolvendo na ALER. Se, no princípio, os boletins e informes eram transmitidos via

\footnotetext{
${ }^{27}$ No original em espanhol: "En un contexto bien complicado, porque fueron entrando en los años 90 fueron los tiempos ya, como decimos en la larga noche oscura del neoliberalismo, de la imposición de los paquetazos, las políticas económicas de los gobiernos que se imprimieron a distintos países, en casi toda Latinoamérica, en fin, con todo lo que significó la profundización de la pobreza como consecuencia precisamente de esas políticas económicas. En algunos países con fuertes conflictos sociales también. (...) Habíamos salido de una etapa de la dictadura, finales de 70, 80, para entrar en esa nueva etapa (...). Entonces que ahí también la agenda era bastante concisa y precisa, que lo delimitamos este anualmente en los talleres que teníamos marcando la línea de lo que se tenía que hacer, con el seguimiento permanente que, desde Quito, también se hacía por parte de la Junta Directiva y del Equipo de Imprensa. Todo un trabajo que lo desarrollamos me parece con mucha firmeza, y con claridad.

${ }^{28}$ No original em espanhol: “Así, desde 1997, ALER tiene un servicio radiofónico de interconexión intercontinental, cuyos soportes principales son el satélite y la Internet”. Disponível em: https://www.aler.org/index.php/node/1. Acesso em: 18 de setembro de 2019.

${ }^{29}$ No original em espanhol: "espacio de encuentro de las radios educativas, populares, comunitarias y participativas".
}

Revista ALTERJOR

Grupo de Estudos Alterjor: Jornalismo Popular e Alternativo (ECA-USP)

Ano 10 Volume 02 Edição $22 \quad$ Juho- Dezembro de 2020

Avenida Professor Lúcio Martins Rodrig̉ues, 443, Cidade Universitária, São Paulo, CEP: 05508-020 
telefone - na substituição das fitas cassetes enviadas por correio -, com uma equipe de jornalismo em funcionamento em Quito (Equador), sede da Associação, a ainda incipiente internet e o satélite passaram a ser utilizados, dando uma nova dinâmica à produção noticiosa entre as emissoras.

A formação de redes propiciada pela tecnologia satelital surtiu um grande impacto entre as associadas, sendo a pioneira na utilização dessa nova tecnologia a Rede Kiechwa Satelital (RKS) ${ }^{30}$, que, já em 1997, levou ao ar a sua programação. O nome da rede, a palavra Kiechwa, é a junção entre kichwas, nação e língua presentes no Equador, e quechuas, que se fincam na Bolívia e no Peru ${ }^{31}$. Além de dezenas de comunicadores pela região, três associações compõem a rede: a Coordenadora Nacional de Rádios (CNR) do Peru, a Educação Radiofônica da Bolívia (Erbol) e a Coordenadora de Meios Comunitários Populares e Educativos do Equador (CORAPE). Com a vocação de valorizar e articular os povos originários, a RKS tem como missão contribuir “à recuperação de seus valores culturais e à superação de sua situação de pobreza e exclusão social e política. Tudo isso na perspectiva de construir uma sociedade justa, solidária, equitativa, democrática e com desenvolvimento sustentável"32.

Ainda que com o crescimento propiciado pelas novas tecnologias, havia pontos de crise no interior da ALER durante esta terceira fase (1992-2001), o que fez com que a Associação desenvolvesse um estudo sobre quais eram o funcionamento, os dilemas e os desafios futuros dessa rede de rádios e das emissoras populares do continente. Esse processo levou à publicação do livro La Radio Popular frente al Nuevo Siglo: Estudio de Vigencia e Incidencia, dos capacitadores da ALER Andrés Geerts e Víctor van Oeyen (2001).

\footnotetext{
${ }^{30}$ Mais informações e programas produzidos pela rede estão disponíveis na página web da ALER. Disponível em: https://www.aler.org/index.php/rks. Acesso em: 20 de fevereiro de 2020.

${ }^{31}$ Apresentação da Rede Kiechwa Satelital no site da ALER. Disponível em: https://aler.org/rks. Acesso em 5 de janeiro de 2020.

${ }^{32}$ Ibidem. No original em espanhol: "a la recuperación de sus valores culturales y a la superación de su situación de pobreza y exclusión social y política. Todo ello en la perspectiva de construir una sociedad justa, solidaria, equitativa, democrática y con desarrollo sostenible".
} 


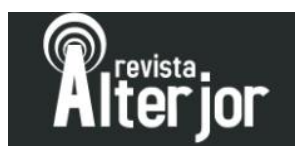

Na obra, uma das discussões levantadas é o uso do termo rádio popular como a identidade da ALER, para demarcar seu alinhamento político-ideológico. Ainda que muitas rádios se identificassem como populares, outras emissoras ou associações fizeram a escolha de definir seu projeto comunicacional como comunitário, alternativo, cidadão ou mesmo educativo. Ao diferenciar histórica e conceitualmente estas experiências, a ALER (GEERTS; OEYEN, 2001) apontou seu entendimento do que é o rádio popular:

Tomando como ponto de partida que os processos de comunicação se desenvolvem dentro de um determinado contexto social, e que este contexto, para os setores populares, se caracteriza por fortes injustiças e desigualdades, o rádio popular é fundamentalmente um projeto de comunicação dentro de um projeto de transformação política. ${ }^{33}$ (p. 32, tradução nossa).

Os questionamentos vindos nos anos 1990 sobre o que se queria dizer com popular, a Associação explica apontando que se trata das maiorias, em que estão a classe trabalhadora, os camponeses e os marginalizados, mas também identificações que vêm pela exclusão de direitos sociais, econômicos e políticos, em função de gênero, etnia, localização geográfica, no sistemas produtivo ou na distribuição de riqueza; são os alvos da discriminação e da desigualdade. Esta reflexão está presente no livro Un Nuevo Horizonte Teórico para la Radio Popular en América Latina (Quito, 1996), que foi marcante nesse período da ALER.

\section{Quarta fase: Projetos Políticos Comunicativos (2001-2011)}

O ponto de virada da ALER da terceira para a sua quarta geração ocorre no ano de 2001, já com 100 sócias e mil vinculadas, em que a Associação se coloca na busca por presença, incidência e identidade no continente (ALER, 2012). Se a primeira formulação da Associação sobre seu papel social e político era chamada de Marco

\footnotetext{
${ }^{33}$ No original em espanhol: "Tomando como punto de partida que los procesos de comunicación se desarrollan dentro de un determinado contexto social, y que este contexto para los sectores populares se caracteriza por fuertes injusticias y desigualdades, la radio popular es fundamentalmente un proyecto de comunicación dentro de un proyecto de cambio político".
} 


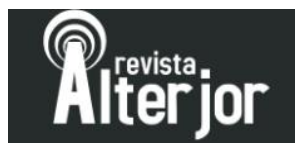

Doutrinário; nos anos 1990 se estabeleceu um Novo Horizonte Teórico; e, a partir dos 2000, a Associação chegou à sua formulação de Projetos Políticos Comunicativos, para si e como um estímulo às associadas.

O contexto da década é uma intensificação do neoliberalismo e da lógica de mercado, gerando ainda mais pobreza, exclusão e desigualdades. A crise econômica mundial de 2008, a partir de uma quebra do sistema financeiro e imobiliário estadunidense, provocou um agravamento das condições de vida da população pobre e dos setores médios em todo o mundo. Ao mesmo tempo, havia "fissuras na visão hegemônica" (ALER, 2008) e novas propostas e cenários políticos despontaram, em especial na América Latina. O início de novos ventos na região se deu ainda no período anterior, com a interrupção de um ciclo conservador e a vitória de um governo de perfil socialista na Venezuela, com a chegada de Hugo Chávez à Presidência do país, em 1999. Nos anos 2000, toma forma a onda de governos progressistas (caracterização ampla, mas que apresenta contradições internas), chegando a nações como Brasil, Argentina, Bolívia, Equador, Uruguai, Paraguai, Chile, Honduras, Nicarágua e El Salvador. "Pela primeira vez na história do continente, temos vários governantes eleitos democraticamente, surgidos das lutas populares. Começam a surgir discursos que haviam sido silenciados no continente" 34 .

Nos anos seguintes, alguns desses governos foram derrubados por golpes de Estado, outros por derrotas eleitorais ou traições internas, ou ainda aqueles que tiveram que reformular sua atuação mais revolucionária em vista dos ataques de grandes potências e devido ao quase isolamento político a que foram submetidos. Ainda que com mudanças na correlação de forças regionais, o cenário de desigualdades permanecia em nível continental e global.

O projeto imperial quer nos impor um mundo unipolar, um modelo de acumulação que não é sustentável nem social, nem cultural, nem econômica e politicamente. Muito menos humanamente.

\footnotetext{
${ }^{34}$ Ibidem. No original em espanhol: "Por primera vez en la historia del continente tenemos varios gobernantes electos democráticamente, surgidos de las luchas populares. Comienzan a surgir discursos que habían sido silenciados en el continente".
}

Revista AL TERJOR

Grupo de Estudos Alterjor:Jornalismo Popular e Alternativo (ECA-USP)

Ano 10 Volume 02 Edição $22 \quad$ Julho- Dezembro de 2020

Avenida Professor Lúcio Martins Rodrig̉ues, 443, Cidade Universitária, São Paulo, CEP: 05508-020 


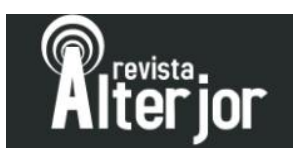

No entanto, vemos com otimismo que cresce a consciência dos povos em torno ao respeito aos Direitos Humanos, o cuidado do ambiente, a necessidade de respeitar a diversidade e a pluralidade cultural, étnica, racial, de gênero, de crenças religiosas, etc. ${ }^{35}$ (ALER, 2008)

Já internamente, a ALER vivia um momento de reposicionar sua estratégia diante do Estado e de outros atores políticos. Desde atuar em políticas públicas como participar em redes, alianças e plataformas amplas em diversos campos (ALER, 2012). Para isso, era necessário construir projetos próprios para si e na relação com a sociedade. Por meio de um método que toma forma com a conformação da Equipe Latino-Americana de Formação (ELFO), na primeira metade dos anos 2000, é implementada uma visão de construir estratégias junto às sócias para definição de Projetos Políticos Comunicativos (PPCs) nas emissoras, ampliando a presença e o alcance das mesmas. Efetivamente, para se construir um PPC, a ALER, por meio de sua equipe de formadores, elaborou uma proposta de trabalho que visava refletir e construir nas áreas de produção de sentidos, incidência e sustentabilidade. Por estes três eixos se chega a um projeto e uma estética próprios. O PPC se propunha a apontar bases ideológicas, políticas e conceituais que serviriam para orientar os passos concretos da experiência radiofônica e enriquecê-los, num ir e vir da teoria e da prática.

Essa era vista pela ALER como a maneira das emissoras garantirem a participação dos setores excluídos da sociedade, garantido-lhes o direito à voz, a expressar-se. E isso se soma ao conceito do rádio popular formulado pela ALER com o adjetivo participativo, recuperando a palavra do povo como sua expressão de poder, que abre aos setores populares o caminho para transformar sua realidade e a sociedade como um todo. O povo e suas formas organizativas passaram a ser vistos como necessidades para estar presentes nos projetos das rádios.

\footnotetext{
${ }^{35}$ No original em espanhol: "El proyecto imperial quiere imponernos un mundo unipolar, un modelo de acumulación que no es sustentable ni social, ni cultural, ni económica y políticamente. Mucho menos, humanamente.

Sin embargo vemos con optimismo que crece la conciencia de los pueblos en torno al respeto a los Derechos Humanos, el cuidado del ambiente, la necesidad de respetar la diversidad y pluralidad cultural, étnica, racial, de género, de creencias religiosas, etc".
} 


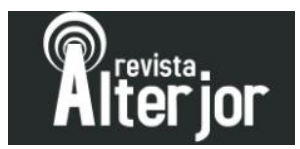

No âmbito das redes temáticas no interior da ALER havia, no período anterior, o fortalecimento da Rede de Correspondentes e da Rede Kiechwa Satelital, e, a partir daí, surgem novas experiências, como a Rede de Migração e a América Indígena em Rede, como relata Hugo Ramírez ${ }^{36}$, atual coordenador-geral da Associação.

\begin{abstract}
A Rede de Migração, pela forte migração que ocorreu em nossos países em direção aos países do Norte, sobretudo o que influenciou muito foi o tema equatoriano, cujos habitantes foram, uma boa porcentagem, para a Espanha; ou na América do Sul e o sonho dos Estados Unidos. Então, essa foi também uma rede muito importante e foram feitos também muitos programas sobre o [tema em] particular e, desde então, esta rede de migração e comunicação permanece aqui na ALER. Depois, também no tema indígena, tivemos, posterior à RKS (Rede Kiechwa Satelital), [a análise de] que o mundo indígena não se centra unicamente nos quechuas e nos kichwas, o mundo indígena vai além dos quechuas e dos kichwas, portanto tínhamos que gerar uma rede maior que agrupe, que articule a tantos povos da Abya Yala. Então, foi criada também América Indígena em Rede. ${ }^{37}$ (informação verbal)
\end{abstract}

Na sequência, foram se articulando outras redes temáticas, como a Rede PanAmazônica de Comunicação, por volta do ano de 2006. Com duração mais efêmeras, a ALER também abrigou redes de jovens - que já não existe mais -, uma rede de educação - que, segundo Ramírez, funciona de uma forma "intermitente" -, e uma rede de evangelização - que funcionou até 2015 ou 2016.

\footnotetext{
${ }^{36}$ Hugo Ramírez, comunicador popular peruano que, desde 2016, é coordenador-geral da ALER, com sede em Quito (Equador), concedeu uma entrevista a esta tese em 13 de janeiro de 2020.

${ }^{37}$ No original em espanhol: "La Red de Migración por la fuerte migración que hubo desde nuestros países hacia los países del Norte, sobretodo influenció mucho por el tema ecuatoriano, cuyos habitantes se fueron, un buen porcentaje, a España; o en Sudamérica el sueño de los Estados Unidos. Entonces esa fue también una red muy importante y se realizaron también muchos programas sobre el particular, y desde entonces permanece también esta red de migración y comunicación aquí en ALER. Después también en el tema indígena tuvimos este, posterior al RKS (Red Kiechwa Satelital), que el mundo indígena no se centra únicamente en los quechuas y los kichwas, el mundo indígena es más allá de los quechuas y los kichwas, por lo tanto tendríamos que generar una red mayor que agrupe, que articule a tantos pueblos del Abya Yala. Entonces se generó también América Indígena en Red”.
} 


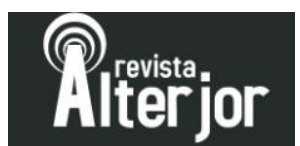

\section{Quinta fase: a aposta pelo Buen Vivir (2011-2020)}

Em seu processo de recriação e elaboração constantes, para manter-se viva e incidindo na sociedade, a ALER, após décadas de construção, se encontra em sua quinta fase, a atual, iniciada em 2011 e com projeção até 2020, com uma aposta em processos para o Buen Vivir.

O Buen Vivir faz a relação entre a harmonia com todos/as nossos/as irmãos/ãs, com as diferentes culturas, com Deus e com a natureza.

O Buen Vivir motiva a viver com abertura a todo mundo e a todas as pessoas em sua diversidades, em busca de uma sociedade mais fraterna, igualitária e justa, ou seja, a grande utopia da fraternidade universal entre todos os povos e raças.

"Vivir bien" se traduz em um imperativo ético e em uma rede de solidariedade para superar as desigualdades, devolver a dignidade a todas as pessoas e elevar a autoestima dos que se encontram deprimidos/as. Promove uma sociedade onde estejam presentes o bem comum, a solidariedade, a colaboração, a equidade, a pacífica convivência. É um convite a nos relacionarmos de um modo distinto com o "outro", aceitando e respeitando tanto a igualdade como as diferenças. ${ }^{38}$ (ALER, 2012, p. 2, tradução nossa)

Estes são alguns dos conceitos formulados pelo conjunto de emissoras associadas da ALER, em um processo que se desenvolveu ao longo dos anos de $2011 \mathrm{e}$ 2012 chamado ALER 2020, que aponta a um novo horizonte para a rede de rádios populares. "O desafio que apresenta [o projeto] ALER 2020 às rádios é repensar o 'para que' da comunicação e da educação popular hoje e em que medida pode ser relevante para contribuir para a construção de comunidades felizes, com modos de vida

\footnotetext{
${ }^{38}$ No original em espanhol: "El Buen Vivir hace relación a la armonía con todos/as nuestros/as hermanos/as, con las diferentes culturas, con Dios y con la naturaleza.

El Buen Vivir motiva a vivir con apertura a todo el mundo y a todas las personas en su diversidad, en busca de una sociedad más fraternal, igualitaria y justa, es decir, la gran utopía de la fraternidad universal entre todos los pueblos y razas.

"Vivir bien" se traduce en un imperativo ético y en una red de solidaridad para superar las desigualdades, devolver la dignidad a todas las personas y elevar la autoestima de los que se encuentran deprimidos/as. Promueve una sociedad donde estén presentes el bien común, la solidaridad, las subsidiaridad, la equidad, la pacífica convivencia. Es una invitación a relacionarnos de un modo distinto con el "otro", aceptando y respetando tanto la igualdad como las diferencias".
}

Revista ALTERJOR

Grupo de Estudos Alterjor:Jornalismo Popular e Alternativo (ECA-USP)

Ano 10 Volume 02 Edição $22 \quad$ Juho- Dezembro de 2020

Avenida Professor Lúcio Martins Rodriģues, 443, Cidade Universitária, São Paulo, CEP: 05508-020 
sustentáveis"39 (CABRAL, 2013, p. 123, tradução nossa). Assim, a Associação bebe na fonte da discussão em torno do Buen Vivir, que vem sendo amplamente feita e marca a política e o modelo de desenvolvimento de alguns países latino-americanos, estando presente, inclusive, nas Constituições da Bolívia e do Equador.

Atualmente, a ALER, articulando mais de uma centena de emissoras na região, tem como projeto político e de comunicação a aposta pelo Buen Vivir, que, para a Associação, tomou corpo dentro da entidade motivado pela busca de "construção de alternativas que protejam e defendam todas as formas de vida" e, também, de "alternativas ao modelo civilizatório capitalista neoliberal que tem sido hegemônico, dominante e violento"40 (ALER, 2016, p. 6, tradução nossa).

Para o presidente da ALER no mandato 2016-2020 e diretor executivo da Associação de Rádios e Programas Participativos de El Salvador (ARPAS), Leonel Herrera Lemus, o Buen Vivir representa um "novo modelo de práticas sociais e modos de vida baseados na relação harmoniosa entre os seres humanos consigo mesmos, seu entorno social e a natureza" ${ }^{41}$ (ALER, 2016, p. 74, tradução nossa).

A iniciativa de trabalhar com a centralidade no Buen Vivir surge em meio a uma crise identitária, de articulação e de participação em diversos níveis na Associação. Assim, a busca por debater com as associadas esse conceito que inspira novas relações e uma maneira de ser e participar no mundo fez com que fossem motivados diversos atores nesse processo. O ponto de partida foi a avaliação de que o modelo de desenvolvimento capitalista se encontrava em uma profunda crise no início do século XXI, "por isso estas são épocas de criatividade e buscas de formas de vida que não estejam centradas no consumo e na exploração indiscriminada dos recursos do planeta". Nesse sentido, baseando-se na comunicação e na educação para a vida, foi feita a

\footnotetext{
${ }^{39}$ No original em espanhol: "El desafío que le plantea ALER 2020 a las radios es repensar el 'para qué' de la comunicación y la educación popular hoy y en qué medida puede ser relevante para contribuir a la construcción de comunidades felices, con modos de vida sostenibles".

${ }^{40}$ No original em espanhol: "Construcción de alternativas que protejan y defiendan todas las formas de vida" e "alternativas al modelo civilizatorio capitalista neoliberal que ha sido hegemónico, dominante y violento".

${ }^{41}$ No original em espanhol: "Nuevo modelo de prácticas sociales y modos de vida basados en la relación armoniosa entre los/as seres humanos/as consigo mismos/as, su entorno social y la naturaleza".
} 


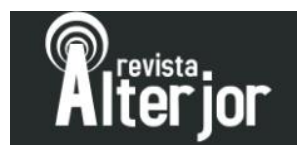

pergunta: "Qual é o lugar e o compromisso que assumem as rádios como projetos político-comunicacionais nessa construção?"42 .

Um longo processo metodológico e formativo, com a mobilização por meio de facilitadores e da Junta Diretiva da ALER, foi realizado em 12 países com 75 rádios. A finalização do projeto ALER 2020 foi a apresentação da síntese final na Assembleia de 40 anos da Associação, celebrada em Quito, Equador, junto com o Encuentro Latinoamericano de Comunicación Popular y Buen Vivir ${ }^{43}$, em 2012.

A partir disso foram reformuladas a missão, a visão, os valores e os princípios da ALER, que passem a ser a base de sua orientação e junto a suas associadas até o presente momento, que, entre outros pontos, destaca que a organização "trabalha pela democratização da comunicação e participa na construção de processos para o Buen Vivir",44.

\section{CONSIDERAÇÕES FINAIS}

Por meio da redefinição e reorientação de sua formulação estratégica, a ALER atravessa quase cinco décadas como uma articulação de comunicação popular incidente e ativa na América Latina. A duração prolongada da rede foi o primeiro fator que chamou a atenção para elaboração de uma pesquisa de doutorado, da qual parte este artigo.

No intuito de compreender quais os fatores que levam a essa longevidade, compreende-se como necessário trilhar um percurso de importantes fragmentos da

\footnotetext{
${ }^{42}$ Ibidem, p. 126. No original em espanhol: "por eso éstas son épocas de creatividad y búsquedas de formas de vida que no estén centradas en el consumo y la explotación indiscriminada de los recursos del planeta"; "¿Cuál es el lugar y el compromiso que asumen las radios como proyectos políticocomunicacionales en esa construcción?".

43 A memória deste Encontro foi organizada e publicada pela ALER como "COMUNICACIÓN POPULAR Y BUEN VIVIR. Memorias del Encuentro Latinoamericano aler 40 años Quito, septiembre 2012. Disponível em: http://www.democraciaycooperacion.net/IMG/pdf/133830222-Memorias-delEncuentro-Comunicacion-Popular-y-Buen-Vivir-En-el-mundo-desde-nuestro-mundo.pdf. Acesso em: 09 de dezembro de 2018.

${ }^{44}$ Trecho presente na visão da ALER. Disponível em: https://www.aler.org/index.php/node/1. Acesso em: 25 de fevereiro de 2020. No original em espanhol: "trabaja por la democratización de la comunicación y participa en la construcción de procesos para el Buen Vivir".
} 


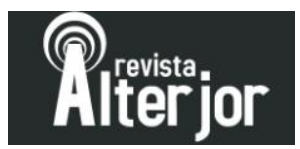

história da Associação, lidos em seu contexto. E é a partir dessa premissa que se estrutura esse artigo. A partir da trajetória da ALER, pode-se levantar alguns pontos de reflexão, a modo de conclusão, sobre elementos que auxiliam na compreensão de redes de comunicação na América Latina e sua relevância.

O primeiro é que a existência e atuação dos meios de comunicação estão colados com a conjuntura, com o momento histórico, e dele se originam suas formulações para se definirem e pautarem sua atuação; no caso da ALER, compreendendo como Associação de emissoras educativas, posteriormente populares, por exemplo.

O segundo é que se faz necessária a autoanálise, um processo de autocrítica, que ajude a identificar os pontos fortes de continuidade e os pontos fracos a se superar; na ALER, passível de visualização em diversos processos, investigações e assembleias em que se buscava fazer um mapa de avaliação própria e das emissoras parte da rede.

Por fim, o terceiro, é que todas as vozes precisam ser escutadas, em um processo de construção coletiva em que os distintos atores, as várias rádios associadas, se sintam parte e identificadas com um projeto comum, por meio do qual não se sintam isoladas, mas parte de um mesmo organismo em comunhão.

Essas são algumas das pistas reflexivas levantadas por essa breve análise da trajetória da ALER a que este artigo buscou-se estruturar.

\section{REFERÊNCIAS}

ALER. Prender para aprender. Uso de la radio en la educación. Quito: ALER, 1993. . Un nuevo horizonte teórico para la radio popular. Quito: ALER, 1996. Un camino a recorrer. Proyecto político comunicativo de la radio popular

latinoamericana. Quito: ALER, 2008. Disponível em: $<$ http://www.gloobal.net/iepala/gloobal/fichas/ficha.php?entidad=Textos\&id=7856\&op cion=documento $>$. Acesso em: 24 de novembro de 2019.

Narración Histórica ALER 2020. Documento produzido em Setembro de 2012. Arquivo interno da ALER.

Siembras del buen vivir. Entre utopías y dilemas posibles. Quito: ALER, 2016.

Revista ALTERJOR

Grupo de Estudos Alterjor: Jornalismo Popular e Alternativo (ECA-USP)

Ano 10 Volume 02 Edição $22 \quad$ Juho- Dezembro de 2020

Avenida Professor Lúcio Martins Rodrig̉ues, 443, Cidade Universitária, São Paulo, CEP: 05508-020 


\section{Aterior}

Un camino a recorrer. Proyecto politico comunicativo de la radio popular

latinoamericana. Aler. Quito, 2008. Disponível em: <http://www.gloobal.net/iepala/gloobal/fichas/ficha.php?id=7856\&entidad=Textos\&ht $\mathrm{ml}=1>$. Acesso em: 17 de outubro de 2019.

BERNAL, César A. Metodología de la investigación. Colombia: Pearson Educación, 2010, tercera edición.

CABRAL, María Cristina. Aportes de la comunicación popular al Buen Vivir. Revista Tram[p]as de la comunicación y la cultura. No 75 / diciembre de 2013. PoP: 126-130. Argentina: Facultad de Periodismo y Comunicación Social / UNLP, 2013.

CHASQUI. La radio educativa. Quito, Equador: Ciespal. No 10, Abr-Jun 1984. Disponível em: <http://revistachasqui.org/index.php/chasqui/issue/viewIssue/10_1984/104>. Acesso em: 08 de janeiro de 2019.

FREIRE, Paulo. Pedagogia do Oprimido. Rio de Janeiro: Paz e Terra, 2005, 42. ${ }^{\text {a }}$ edição.

GEERTS, Andrés; OEYEN, Víctor van. La radio popular frente al nuevo siglo: estudio de vigencia e incidencia. Quito, Equador: ALER, 2001.

KAPLÚN, Mario. Una Pedagogía de la Comunicación. La Habana: Editorial Caminos, 2002. 240 p.

MATA, María Cristina. Radio popular o comunitaria. Quito, Equador: Chasqui $\mathrm{N}^{\circ} 47$, Nov. $1993 . \quad$ Disponível em: <www.revistachasqui.org/index.php/chasqui/article/view/2152/2172>. Acesso em: 21 de setembro de 2017.

PROAÑO, Luis E. La Radio Educativa en América Latina. Revista Chasqui, Quito, Equador: Ciespal. $\mathrm{N}^{\circ}$ 10, p. 2-3, Abr-Jun, 1984. Disponível em: <http://revistachasqui.org/index.php/chasqui/issue/viewIssue/10_1984/104>. Acesso em: 08 de janeiro de 2019.

SILGUERO, Ricardo. Once años de ALER. [Entrevista concedida a] Eduardo Contreras Budge e Ronald Grebe López. Revista Chasqui, Quito, Equador: Ciespal. № 10, p. 411, Abr-Jun, 1984. Disponível em: <http://revistachasqui.org/index.php/chasqui/issue/viewIssue/10_1984/104>. Acesso em: 08 de janeiro de 2019.

VELASCO, Javier. Once años de ALER. [Entrevista concedida a] Eduardo Contreras Budge e Ronald Grebe López. Revista Chasqui, Quito, Equador: Ciespal. N 10, p. 411, Abr-Jun, 1984. Disponível em: <http://revistachasqui.org/index.php/chasqui/issue/viewIssue/10_1984/104>. Acesso em: 08 de janeiro de 2019. 